\title{
Defence Commitment and Deterrence in the Theory of War
}

\author{
Vesa Kanniainen \\ University of Helsinki, HECER, CESifo and \\ the National Defence University, Helsinki
}

Discussion Paper No. 426

February 2018

ISSN 1795-0562

HECER - Helsinki Center of Economic Research, P.O. Box 17 (Arkadiankatu 7), FI-00014 University of Helsinki, FINLAND,

Tel +358-2941-28780, E-mail info-hecer@helsinki.fi, Internet www.hecer.fi 


\title{
Defence Commitment and Deterrence in the Theory of War*
}

\begin{abstract}
The paper shows that a defending army, particularly a small one, can fight hard when attacked by a predator. The result arises in the commitment equilibrium of a model with intergenerational altruism. By implication, the paper offers a novel theory of deterrence and defence policy. It shows that in the absence of informational constraints, there is a unique army size that is sufficient for deterrence. Under informational restrictions, a pooling equilibrium may exist where a victim with strong intergenerational altruism overinvests in its army, while the victim with a more limited altruism free rides on the information gap of the predator and builds a smaller army. Conditions for the existence of a separating equilibrium are established in terms of the cost of war. It turns out that the optimal defence policy need not satisfy the deterrence requirement. The case of separating equilibrium helps to explain why wars exist in equilibrium.
\end{abstract}

JEL Classification: H12, H56

Keywords: national security, theory of soldier, commitment to defend

Vesa Kanniainen

Economics

P.O. Box 17 (Arkadiankatu 7)

FI-00014 University of Helsinki

FINLAND

e-mail: vesa.kanniainen@helsinki.fi

* Prepared for the CESifo workshop, "The Economics of Peace and War", Venice, July 2021,2016 . The author is grateful to the Foundation of Supporting for the Finnish Society for a grant for this study. Moreover, the author acknowledges with gratitude the helpful comments by Brett Benson, Tuomas Malinen, Ilkka Mellin, Juha A. Mäkinen, Teemu Tallberg, and Kari Vitie. Highly valuable suggestions by two referees and the editor led to substantial improvements of the paper and are gratefully appreciated. 


\section{Introduction}

The regularities and motives of war have been the subject of a large body of military studies. ${ }^{1}$ In the current paper, a particular type of war is under focus: asymmetric warfare between two countries with different military strengths. Large empires in particular, tend to control and even attack on their smaller neighbors. ${ }^{2}$ This paper studies an asymmetric war in the spirit of the predator-victim framework, addressing two related issues: (i) why does a smaller victim fight harder than a larger predator, and (ii) what are the implications of such commitment to deterrence and defence policy?

Over the course of history, no common motivation for war in general is available. Political science views appear to acknowledge the geopolitical factors. Economists have mostly considered wars as contests, largely neglecting other motivations for warfare. The proposal that the victims often fight harder than the predators is not new (cf. Hirshleifer (1991)). Motivational determinants apparently need to be integrated into the theory in a deeper and more consistent way to explain such behaviour. ${ }^{3}$ The paper introduces an economic approach building on the biological and evolutionary foundation advanced by Hirshleifer (1998). A unique feature of the model is that soldiers choose how much warfighting risk to take on themselves as a building block for the theory of defence and deterrence. The paper introduces a well-defined intergenerational altruistic preference structure of individual fighters in conditions where the risk of death is the choice variable. The survival probability of the offspring is part of the altruistic preference structure of the individual soldiers. ${ }^{4}$ To further motivate such a research agenda, the

\footnotetext{
${ }^{1}$ The survey by Levy (1989), for example, has 800 references.

${ }^{2}$ The literature has long differentiated the cases of defensive and offensive wars (see Arce, Kovenock and Robertson (2012) and the papers there). Alesina and Spolaore (2003) have suggested a theory of (peaceful) formation of country size in terms of public goods and heterogeneity of preferences. They also study the connection between conflicts and the size of nations.

${ }^{3}$ In his Bioeconomic Causes of War, Hirshleifer (1998) concluded that "in biological terms the ultimate functional motives for fighting are food and sex, the essential elements for reproductive success. Like many other animals, humans seek food and sex directly, but also indirectly via dominance or prestige. But, although largely disconnected from reproductive success, intangible goals such as prestige, dominance, and respect - amplified by the 'affiliative instinct' - remain with us as continuing causes of war".

${ }^{4}$ Adam Smith wrote: "Every man feels his own pleasure...After himself, the members of his own family...are naturally the objects of his warmest affections" (Smith (1853), p. 321). In Becker (1991), altruism is viewed as the primary motive for intergenerational
} 
current paper recalls that it is indeed the fight of the current generation for the survival of its offspring that is the fundamental mechanism in all nature. This concerns all living creatures, even including plants. ${ }^{5}$

The literature on military studies justifies the view that motivational reasons for war, conflict, and aggression are many. The soldiers can care about a country winning the war for a number of reasons. ${ }^{6}$ Such a psychoanalytic view was advanced by Fornari (1975), who claimed that sacrifice is the essence of war: it translates into the willingness of humans to die for their country. Of course, the paper does not challenge the literature of the military studies or of other motives. Our paper suggests that when it is a matter of survival for a victim to resist an attack by a stronger predator, the fundamental altruistic motives may become relevant. This concept is supported by many examples. ${ }^{7}$ In 480 BC, the vastly outnumbered Greeks held off the Persians for seven days in the battle at the pass of Thermopylae in the most remarkable defence battle in history. In 1565, 700 Johannite knights and 8000 Maltese soldiers successfully defenced Malta island against an Ottomans attack by an army of 40 000, more than four times greater. The Vietkong guerrillas were able to beat the more advanced US army during the 1960s. In the three-and-a-half-month Winter War of 1939, the Finnish army stopped Stalin's Red Army (though it was three times stronger), and did so for the second time in 1944 in the Battle of Tali-Ihantala (with the Red Army having four times the superior power), the largest-ever battle in the Nordic countries. Moreover, though it was five times larger, the Russian Red Army was defeated when it attacked the smaller German-Estonian defence forces at the Siltamäe battles in July and August 1944 causing a substantial loss of

family relations.

${ }^{5}$ The fight for fitness is a neverending process at all levels of life. The metaphor of the "selfish gene", introduced by biologist Richard Dawkins in the 1970s, has established its place as the fundamental law of life. William Hamilton, another biologist, had established the role of kinship in this process, while others have qualified it subsequently. At the highest level of conflict, the fight is between various species.

${ }^{6}$ The motives, as suggested by one of the referees, may include the pride of being part of a grand and victorious nation, dreaming of a posthumous plaque at a future victory monument, etc.

${ }^{7}$ As the referee correctly points out, the analytic solution of the model world of the current paper does not depend on the background motivational "story". When competing theories for individual choices are around, the economic approach must be based on specifying the underlying preferences, derivation of propositions concerning behaviour, and asking what the tastable implications are. 
men. ${ }^{8}$

The economic theory of conflicts was initiated by Schelling $(1960,1966)$. Based on Tullock $(1967,1980)$, tools for an economic approach to the theory of conflicts have addressed the question of the likely winner in a conflict and subsequently extended to a large research area by Hirshleifer (1991), Bueno de Mesquita and Lalman (1992), Bueno de Mesquita, Smith, Siverson and Morrow (2003), Jackson and Morelli (2007), and Beviá and Corchón (2008). Konrad (2009) elaborated and extended this work in several directions. Benson, Meirowitz and Ramsay (2014) showed that the effect of moral hazard in alliances can improve security. Spolaore and Wacziarg (2016) examined the occurrence of interstate conflicts and the degree of relatedness between countries. The issue of the commitment of individual soldiers to the national defence has been addressed in sociological and psychological research by a number of authors, including Salo $(2011)^{9}$, Nokkala $(2014)^{10}$ and Sinkko $(2015)^{11}$ among others. The paper introduces first an analysis of the risktaking and commitment of an individual soldier in providing the defence effort in a predator-victim model. Each individual soldier is risk averse and is assumed to face the risk of death resulting both from exogenous reasons beyond his control and from his own choice in a conflict situation. It is then

\footnotetext{
${ }^{8}$ Those successful defence battles appear to qualify the position by von Clausewitz (1943, p. 293) stating that "...one will search in vain for a battle in which the winning side triumphed over an army twice its size".

${ }^{9}$ In Salo (2011), the unit cohesion was understood as a process of social integration among members of a primary group with its leaders and the larger secondary groups of which they are a part. The results showed that platoons with strong primary-group cohesion differed from other platoons in terms of performance, training quality, secondarygroup experiences, and attitudes towards refresher training. At the sociometric level, soldiers who were chosen as friends by others were found to be more likely to have higher expected performance, better performance ratings, more positive attitudes towards military service, higher levels of well-being during conscript service, and fewer exemptions from duty during it. At the group level, the selection of the respondents' own group leader rather than a leader from outside (i.e., leader bonding) had a bearing not only on cohesion and performance, but also on the social, attitudinal, and behavioural criteria. The sociological studies on the motives of the soldiers also include Shils and Janowitz (1948), Siebold (2007), and Wong, Kolditz, Millen and Potter (2003).

${ }^{10}$ Nokkala (2014) suggested in particular that the ability to defend is determined by commitment.

${ }^{11}$ In his survey among the draftees, Sinkko examined the relation between the commitment to defend and the trust of a soldier in himself and in the group, the social capital among the draftees, and several psychological mechanisms. For studies in cooperative behaviour in groups, a reference can be made to Kolmar (2013).
} 
assumed that the risky operations call for collective actions and group cohesion. In particular, the commitment of providing a risky effort is assumed to arise from the intertemporally altruistic preference towards the offspring. The soldier values both his own life and the life of his child. The defence effort of the soldiers results in an externality on the safety of the civilians. An individual soldier, however, is assumed to value the externality on the life of his child alone, not on the life of co-citizens and their children. The paper shows that in the commitment equilibrium, there is no underprovision of effort. ${ }^{12}$ Moreover, though the created national security is a non-excludable public good, the civilians who free ride on the externality are financing its production through their tax liability. When building its national security, a potential victim hopes to communicate to the predator that it is committed to defending itself, by investing ex ante in defence. Under informational asymmetries, however, it may be difficult to convincingly communicate such a commitment.

The main results of the paper are as follows. In the commitment equilibrium, intergenerational altruism can explain why the defending army fights hard, and even more so when the predator's military capacity is large. Small armies in particular fight harder than large armies. The implications for deterrence and defence policy are shown to be important. Indeed, the second set of results concerns the optimal size of the army. In the absence of informational constraints, there is a unique army size for deterrence. Under informational restrictions, a pooling equilibrium may exist where a victim with strong intergenerational altruism overinvests in its army while the victim with a more limited intergenerational altruism free rides on the information gap of the predator building a smaller army. Conditions for the existence of a separating equilibrium are established in terms of the cost of war. A victim with a high perceived cost of war tends to be willing to build a large army as a costly signal with the purpose of being differentiated from a victim with a lower perceived cost of war. It turns out that the optimal defence policy need not satisfy the deterrence requirement, but rather the optimal army size is determined by the elasticities of the utility with respect to the tax cost and the probability of victory relative to the army size. The case of separating equilibrium helps to explain why wars exist in equilibrium.

\footnotetext{
${ }^{12}$ Intuitively, a commitment equilibrium represents a state where the soldiers of the defending army collectively provide a risky defence effort which is in line with the probabilistic survival of themselves and of their offspring.
} 


\section{Life and Death: a Model of a Soldier}

\subsection{Military threat and national defence budget}

The war game between a predator and a victim is asymmetric. The predator is a ruthless aggressor aiming at capturing the resource of the victim, $R$. There are two stages in the model world of Section 2. In stage 0, the victim becomes the subject of a threat from the predator. ${ }^{13}$ To deter the aggression, the victim invests in its national defence ex ante to establish a credible commitment to defence communicating such a commitment to the predator. In stage 1 , the threat is deterred or will break out as a war. The victim has the option of surrendering in stage 1 .

The adult population of the victim country is a mass of size $N>>1$. In stage 0 , part of the population of the victim is drafted or employed in the military. There are two types of careers in the victim country, a civilian career and a soldier career. ${ }^{14}$ The size of the victim army is the optimising variable of the victim and is denoted by $n$. The size of the adult civilian population is thus $N-n$. Each (civilian and military) adult has one child. Thus, the total population in the victim country is $2 N .^{15}$

The income of each civilian adult in stage 0 is $Y=Y(R), Y^{\prime}(R)>0$ where $R$ is the resource of the victim. It is lost if the war is lost. If the war is deterred or the attacker defeated, the economy remains stationary with the civilian income remaining at the level $Y$, net of the potential cost of the war.

The civilian income is used to finance the consumption of the civilians, $\hat{C}$, of their children, $\hat{c}$, and of the soldiers, $C$, and their children, $c$, through the defence budget, which is tax-financed. If the war is lost, the consumption by all society members falls and is set to zero, if only to simplify the notation.

It will be assumed that the consumption within the civilian career equals

\footnotetext{
${ }^{13}$ One can think that in stage -1 , the predator has invested in its military strength to subsequently capture the victim.

${ }^{14}$ It is easiest to think that the defence army in the current model is based on a stochastic draft. Kanniainen and Ringbom (2016) show how the theory of a voluntary army can be developed to include the non-arbitrage condition between the civilian and military remuneration in civilian and military careers. Earlier, a similar condition was worked out by Poutvaara and Wagener (2007). If there is heterogeneity in intergenerational altruism, then altruism is also likely to drive the selection of soldiers into professional armies as one of the referees has suggested.

${ }^{15} N$ and $n$ can be thought of as integers. In the subsequent analysis, they are employed as if they were continuous variables whenever derivatives are developed with respect to them. This is to avoid the use of cumbersome $\triangle$ - operations.
} 
for all adults and children, and the same holds true for the soldier careers. The social contract dictates that the expected utilities of the two types of careers, to be denoted later in the paper by $E[U]$ and $E[V]$, are equalised through the tax system. ${ }^{16}$ Civilian adults pay a tax $T$ from their income to be allocated to finance the living costs of the soldiers and their children. Thus, the consumption of a civilian adult in stage 0 is

$$
\hat{C}=Y-T-\hat{c}
$$

and is similar in stage 1 if the victim is able to defeat the predator. The defence budget in stage 0 then is

$$
D=(N-n) T=n(\hat{C}+\hat{c})
$$

The required tax revenue to finance the defence budget is thus

$$
T=\frac{2 n}{N-n} \hat{C}
$$

\subsection{Risk of death}

Each soldier faces the risk of a premature death arising from two sources. First, there is an exogenous risk of death, which is inversely related to the size of the army. The exogenous source of risk is always present in military confrontations and a soldier cannot insure against it. The probability of death for the exogenous reason for each soldier is taken as $\sigma\left(n / n_{P}\right), \sigma^{\prime}(n)<0$, i.e. it is negatively related to the size of the defending army relative to that of the predator, $n / n_{P} .^{17}$

The second source of risk is endogenous. It arises from the risky defence effort by an individual soldier, $i$, and is denoted by $e_{i}$. It is measured by the endogenous probability of death, satisfying $0 \leq e_{i} \leq 1$. The residual probability of surviving then is $1-e_{i}$. The two risk sources are taken to be

\footnotetext{
${ }^{16}$ One can think that the social contract involving a (more) risky military career demands a risk premium requiring $C>\hat{C}$, as the civilians outsource the risk of death to the soldiers. One way to introduce such a scheme is to build a fund to finance the consumption of the children of the soldiers who die. The current model abstracts from this qualification.

${ }^{17}$ The exogenous risk is included for completeness. It does not interact with the incentive conditions studied below.
} 
independent random variables. ${ }^{18}$ Though a soldier faces the risk of death, there is also a risk-free option with $e_{i}=0$, i.e., the option of fleeing representing a corner solution. ${ }^{19}$

It is assumed that the probability for the victim country to successfully resist the attack and thus to win the defence war is given by $0 \leq P \leq 1$ if the war breaks out. The war is costly for both the victim and the predator. The costs are measured by $n_{P} k$ and $n K$ for the victim and for the predator, respectively, where $k>0, K>0$.

\subsection{Intergenerational altruism}

In the formal model, the soldiers are expected utility maximisers optimising their death probabilities. ${ }^{20}$ A soldier values his own life and the life of his child. He does not value the life of his fellow citizens - unless they are relatives. ${ }^{21}$ For each individual soldier, the state of the world is a binary random variable. The soldier chooses the risk level of his action in terms of the probability that he is alive, $0 \leq 1-e_{i} \leq 1$, and dead, $0<e_{i}<1$. The degree of commitment is a continuous decision variable. Risk -loving action is not excluded. ${ }^{22}$

For the children of the soldier and of the civilian, the state of the world is a binary random variable, too. A child may or may not survive. He

\footnotetext{
${ }^{18}$ Risk-taking at a higher level in military decisionmaking is quite another issue and separate from individual risk-taking. In war, fundamental choices are undertaken by the leaders, not by the individual soldiers. This explains the exogenous source of risk. The motives of the leadership are essential to understand as they determine the exogenous risk of death. If the size of the army is large, the leaders can take greater risks: then the risk of the army being totally destroyed is small. The risk tolerance of the leadership, then, is large. This illustrates that the presence of the exogenous source of risk has nothing to do with the altruistic motive of a soldier. In a military conflict, the leadership has to value the life of a soldier as part of a strategic choice. The soldier himself, however, values his life relative to the life of his offspring.

${ }^{19} \mathrm{An}$ argument is often stated that draftees fight for their families while professional ones fight for the money. This argument fails if the draftees do not have a family and the professionals do. However, those in a reserve typically have offspring, which creates the incentives studied in the current paper.

${ }^{20}$ This is not to deny that the risk-taking in the operations is partly based on intuition and partly on rational choice, cf. Sutherland (2011). In a more general model of safety production, manpower and technology can be combined in the production function of national safety.

${ }^{21}$ This is based on Hamilton (1964).

${ }^{22}$ Recall the Japanese kamikaze suicide pilots!
} 
or she survives only if the war does not break out or if the victim defeats the attacker. An individual soldier is unable to make a difference as to the probability of the victory of the war, but the army as a whole can.

The expected utility of an individual soldier is assumed to be cardinal and with intergenerationally altruistic preferences stated as $^{23}$

$$
E\left[U\left(C\left(e_{i}\right), c\left(e_{i}\right)\right)\right]=\sum_{\tau} \pi_{\tau} F\left[u\left(C_{\tau}\left(e_{i}\right)\right), v\left(c_{\tau}\left(e_{i}\right)\right],\right.
$$

where the function $F$ will be speficied below, where the probabilities of the states of the world are $\pi_{\tau}$ and where the consumption of the soldier and the consumption of his offspring - to be repeated - are $C, c$, respectively.

The partial derivatives of the utility function are positive; the second partials are negative,

$$
u(0)=v(0)=0, u^{\prime}(C)>0, u^{\prime \prime}(C)<0, v^{\prime}(c)>0, v^{\prime \prime}(c)<0 .
$$

In what follows, a simplication will be introduced with $u(C)=v(c)$ when $C=c$. If the war breaks out, there are ex post four possible states of the world in the model for each soldier: (i) the victim country is successful in its defence, the soldier is alive and the child survives, (ii) the soldier dies but the war is won and the child survives (iii) the war is lost, (hence) the soldier dies and the child does not survive, and (iv) the war is lost but the soldier survives. ${ }^{24}$ The probabilities of the states of the world are $\pi_{i}^{d}=$ $\left(\left(1-e_{i}\right) P, e_{i} P, e_{i}(1-P),\left(1-e_{i}\right)(1-P)\right)$. Under non-survival, consumption and utility are zero. When the war is lost, the predator confiscates the resource $R$ of the victim. Without losing generality and if only to economize in notation, it is taken that the consumption of the victim population is zero

\footnotetext{
${ }^{23}$ It is explicit from this formulation that the soldier disregards the externality of his action on the civilians and their children, who actually benefit from the public good nature of the national defence. Kahnemann and Tversky (1979) have suggested in their influential work that people are more inclined to avoid the loss rather than the gain in risky choices. This proposal appears particularly relevant in matters of life and death. The current analysis, based on the expected utility theorem, is subject to this criticism. However, it can be motivated as a first step in introducing the analysis if risk-taking under intergenerational altruism.

${ }^{24}$ Notice that in case (iii), the soldier dies when fighting, but in case (iv) he dies because of zero consumption.
} 
when the war is lost. The associated consumptions of the soldier families are $(C, c),(0, c),(0,0),(0,0)$.

To develop the expression for the probability of winning the war, $P$, it is appropriate to invoke the idea of Tullock (1967, 1980). Konrad (2009) extended this approach to the case where an alliance of players contests against a third player. The alliance approach can be extended to model a war between two armies. Based on the additivity property in success, the model predicts the probability of victory in the war between $n_{P}$ soldiers of the predator and $n<n_{P}$ solders of the victim as follows

$$
P=\frac{\sum_{i=1}^{n} e_{i}}{\sum_{i=1}^{n} e_{i}+\sum_{i=1}^{n_{P}} E_{i}} .
$$

Here $E_{i}$ is used to measure the military effort of the soldiers in the predator army, taken to be exogenous. As the child of a soldier of the predator army soldier is not at risk, and it is appropriate to think of differentiated incentives, $e_{i} \geq E_{i}{ }^{25}$

Abstracting for a moment from imperfect commitment, it is appropriate to introduce the notation $e_{i}=e^{*}, E_{i}=E^{*}$ to point to committed uniform risk-taking. Then the above expression simplifies to

$$
P\left(n, e^{*}, N, E^{*}\right)=\frac{n e^{*}}{n e^{*}+m} .
$$

where the military strength of the predator is expressed as $m=n_{P} E^{*}$. The aggregated military strength will be denoted by $M=n e^{*}+m$. Clearly, the winning probability is strictly concave in $e^{*}$ for $0 \leq e * \leq 1 ; \partial P / \partial e^{*}=$ $n m / M^{2}>0, \partial^{2} P / \partial e^{* 2}=-2 n^{2} m / M^{3}$. Commitment gives rise to mutual externalities as the effect of individual commitment is limited to $m / M^{2}<$ $n m / M^{2}$. However, in commitment equilibrium, no underprovision of safety arises. As the expression $P\left(n, e^{*}, N, E^{*}\right)$ is rather cumbersome, a shorter version will occationally be introduced.

For the subsequent analysis below, it is helpful to evaluate the welfare measures under different scenarios. Those include: (i) successful deterrence, (ii) failing deterrence where the conflict breaks out into a war, and (iii) the victim surrendering without a fight.

\footnotetext{
${ }^{25}$ One should distuingish "winning a war" from "winning a battle" if the war consists of a series of battles.
} 
(i) Successful deterrence Under successful deterrence, the welfare of the victim is

$$
\begin{aligned}
W(\hat{C}, \hat{c}, C, c) & =(N-n)\{U(\hat{C}(Y, \hat{c}, T, n))+U(\hat{c})\} \\
& +n\{U(C(e))+U(c)\} .
\end{aligned}
$$

To explicate, the cost of war is avoided and the welfare is equal to the sum of the utilities.

(ii) Failing deterrence The case of failing deterrence means that the victim suffers a sunk cost $n_{P} k>0$ from the war related to the size of the predator army. Moreover, the outcome of the conflict is uncertain. The probability of a successful resistance, however, remains positive for the victim and is given by $P$. Its expected welfare is

$$
\begin{gathered}
E[W(\hat{C}, \hat{c}, C, c)]=(N-n)\{E[U(\hat{C}(Y, \hat{c}, T, n))]+E[U(\hat{c})]\} \\
+n\{E[U(C(e))]+E[U(c)]\}-n_{P} k .
\end{gathered}
$$

(iii) Surrendering The option of surrendering can be exercised if the cost of war is considered large. When surrendering, the welfare of each member in the population of a surrendering victim is assumed to be given by the utility of an exogenous survival income level $Y_{0}$;

$$
W^{s}=n W\left(Y_{0}\right) \text {. }
$$

The option of surrendering has value only if the welfare under surrendering exceeds the expected utility under fighting. Thus, the option value can be stated as

$$
v=\max \left[0, W^{s}-E[W(\hat{C}, \hat{c}, C, c)]\right]
$$

Interesting enough, the predator may have an incentive to promise a sufficient survival income $Y_{0}$ to induce the victim to surrender without fighting, though at the expense of losing the resource $R .^{26}$

In the analysis below, it will become important to evaluate the ranking of the three alternative outcomes,

\footnotetext{
${ }^{26}$ Under surrendering, the predator has no reason to retaliate.
} 


$$
\left\{W(\hat{C}, \hat{c}, C, c), E[W(\hat{C}, \hat{c}, C, c)], W^{s}\right\}
$$

\subsection{Commitment to risky action under risk aversion}

The expected utility of each soldier (4), assumed to be additively separable and expressed through the $F$-function in (4), will now be specified as

$$
E\left[U\left(e_{i}\right)\right]=\left(1-e_{i}-\sigma\left(n / n_{P}\right)\right) u(C)+\theta P\left(n, e_{i}, e_{-i} *, m\right) v(c) .
$$

where a shorter notation $E\left[U\left(e_{i}\right)\right]=E\left[U\left(C\left(e_{i}\right), c\left(e_{i}\right)\right)\right]$ has been adopted. In this welfare expression, the parameter $\theta>0$ measures the valuation of the life of the future generation by the current generation. Verbally, the expected utility of the soldier is the sum of the utility of being alive multiplied by the probability of being alive and the utility of the next generation conditional on the victory of the victim country. In (11), $e_{i}$ is the decision of soldier $i$ and $e_{-i} *$ is the collective decision of the rest of the soldiers. The first-order condition of soldier $i$ is given by

$$
E\left[U^{\prime}\left(e_{i}\right)\right]=-u(C)+\theta\left(\frac{\partial P\left(n, e_{i}, e_{-i} *, m\right)}{\partial e_{i}}\right) v(c)=0 .
$$

Recall the assumption $u(C)=v(c)$ when $C=c$. Use $\partial P / \partial e_{i}=m / M^{2}$ from (5) to arrive at,

$$
e_{i}=\frac{\sqrt{\theta m}-m}{n}
$$

A soldier may opportunistically access a risk-free choice $\left(e_{i}=0\right)$ at the corner. But then, if all soldiers behave similarly, the next generation has no future. The equilibrium outcome is lost war. It can be called a chicken equilibrium. Therefore and under joint commitment, a soldier with a higher $\theta$ is ready to take some risk of death, $e_{i}>0$, at the cost of the reduced probability of surviving himself, $1-e_{i}<1$. However, there is a limit: as shown below, the expected utility of a soldier is strictly concave in the death probability $e_{i}$, catching his risk aversion towards the risk of death. Empirical examples of such an equilibrium are many. From here on, the current paper will focus on the commitment equilibrium. A question is raised about what 
the collective risk-taking has to be for maximising the expected utility. ${ }^{27}$ We state.

PROPOSITION 1. Under unified commitment, $e_{i}=e *$ for all $i$, and if $m / n<\theta<(n+m)^{2} / m n$, the utility maximising commitment is given by

$$
e_{i}=e *=\frac{\sqrt{\theta m n}-m}{n}
$$

PROOF. The objective function is continuous with continuous derivatives everywhere. The effect of risky effort on the probability of victory is positive,

$\partial P(n, e *, m) / \partial e *=n m / M^{2}>0$. Then (14) qualifies as the unique interior solution under collective commitment if it satisfies $0<e^{*}<1$, which holds for

$$
m / n<\theta<\frac{(n+m)^{2}}{m n} .
$$

The second-order condition for an interior maximum at $0<e^{*}<1$ is

$$
E\left[U^{\prime \prime}(e *)\right]=\frac{\partial^{2} E\left[U\left(e^{*}\right)\right]}{\partial e *^{2}}=-\theta \frac{2 n^{2} m}{M^{3}}<0,
$$

which is satisfied. QED

The utility function adopted therefore exhibits risk aversion. It is a bit more complicated than the standard expression as behavioral characterisation because it captures the idea of collective commitment of the defence group. There is more to it. If it is the case that the intergenerational altruism $\theta$ is bigger than the stated upper limit, $\theta>\frac{(n+m)^{2}}{m n}$, the solution satisfies $e^{*}=1$ what can be called a kamikaze equilibrium. Alternatively, if $\theta<m / n$, we have $e^{*}=0$. Note that the fighting intensity depends both on $\theta$ which is a parameter and $n$ which is a policy variable. In what follows, our focus will be in the equilibrium where their joint impact maintains the condition $0<e^{*}<1{ }^{28}$

\footnotetext{
${ }^{27}$ One of the referees has called this a planner's solution, which is fully appropriate.

${ }^{28}$ The choice of an individual soldier depends on his expectations concerning the choice of the co-soldiers. If no one is committed, the war will be lost for sure and there is no gain for an individual soldier to commit himself alone. The war equilibrium is thus conditional on expectations and the case of multiple war equilibria can arise as follows. The army is a collective group of individuals with private knowledge of their capability of committing to risky actions. It is privately optimal opportunistically to deviate from the collective action given the expectations that the co-soldiers do not. Commitment has a strong presence in
} 
Some additional results are reported:

COROLLARY 1. The intergenerational altruism has a positive impact on risk-taking

$$
\frac{\partial e^{*}}{\partial \theta}>0
$$

PROOF. Straightforward.

COROLLARY 2. The military strength of the enemy makes the soldiers of the victim take more risk, $\partial e^{*} / \partial m>0$ if $\theta>4 m / n$.

PROOF. Straightforward.

The next result is rather important. It proves Hirshleifer's (1991) view in the current framework.

PROPOSITION 2. Under uniform commitment and with sufficiently large intergenerational altruism, $(\theta>4 \mathrm{~m} / n)$ soldiers in a small army fight harder than in a large army.

PROOF. Differentiating,

$$
\frac{\partial e *}{\partial n}=\frac{1}{n^{2}}\left[-\frac{1}{2} \sqrt{\theta m n}+m\right] \text {. }
$$

Thus,

$$
\frac{\partial e *}{\partial n}<0
$$

if and only if

$$
\theta>\frac{4 m}{n} \cdot Q E D
$$

the celebrated war film "The Thin Red Line" by Terrence Malick. To eliminate the opportunism, punishments are needed to support the individual commitment. When Stalin's Red Army attacked Finland in 1939 and 1944, the attacking troops were fired upon not only by the Finns from the front. The fleeing soldiers were fired also by the Soviet military from the back to impose the commitment of attacking. Wikipedia reports: "During World War II, NKVD Internal Troops units were used for rear area security, including preventing the retreat of Soviet Union army divisions. Though mainly intended for internal security, NKVD divisions were sometimes used at the front to stem the occurrence of desertion through Stalin's Order No. 270 and Order No. 227 decrees in 1941 and 1942, which aimed to raise troop morale via brutality and coercion." 
However, a small army always remains weaker than a larger one in that the total military strength, $n e^{*}$, increases with army size:

COROLLARY 3. The total military strength, ne*, increases with army size.

PROOF. Evaluating,

$$
\frac{\partial(n e *)}{\partial n}=\frac{1}{2 n} \sqrt{\theta m n}>0 . Q E D
$$

Moreover, the probability of winning a war increases with army size, though at a declining rate. Denoting in short $P=P(n)$,

COROLLARY 4. The probability of victory, $P$, is strictly concave in the size of the committed army, $n, P^{\prime}(n)>0, P^{\prime \prime}(n)<0$.

PROOF. The proof is obtained by straightforward derivation.

Thus, though the total military strength is increasing in the army size, it is increasing at a declining rate. This follows from the effect of the army size on the fighting effort of the soldiers.

The results of the current section on the collectively optimal effort provision have a useful interpretation. Mutual effort provision results in external effects in that the offspring of all soldiers benefit from the effort provision of all co-soldiers. The externalities are effectively internalized. ${ }^{29}$ These results have implications for the optimal design of the defence strategy at the national level to be studied next.

\section{Building the Defence to Deter an Attack}

Consider the case where deterrence is considered as the desired national target. To deter an attack, the victim builds an army, which raises the threshold for the predator sufficiently to keep it indifferent between attacking and not

\footnotetext{
${ }^{29}$ The author is indebted to one of the referees for a helpful evaluation of the results of this section. There is a further extension of the model, though not included in the current paper. From the point of view of life insurance, each soldier's best strategy is to keep his partner, the co-soldier, alive. This model could easily be extended to incorporate this mechanism, which would further enhance the incentive of risk-taking. Levine and Modica (2016) show that free riding problems can be overcome through costly peer punishment, creating self-sustaining group discipline.
} 
attacking. In this section, the case of perfect information is considered. ${ }^{30}$ Informational constraints complicate the analysis and are considered in Section 4. Having a large army raises the social cost of public funds, reducing consumption at the margin. There is also a gain: the cost of war to the predator, $n K$, increases in the investment of the victim. The victim has communicated to the predator its commitment to defend i.e. $n e^{*}$. The predator faces the question of whether to attack or whether to give up. Given the defence commitment of the victim, $e^{*}$, the probability of the victory is $1-P\left(n, e^{*}, m\right)$ for the predator. Then, the predator is indifferent to attacking or giving up if the expected gain satisfies

$$
E\left[\Pi_{P}\right]=\left[1-P\left(n, e^{*}, m\right)\right] R-n K=0 .
$$

This condition states the deterrence condition. Recalling $\partial P / \partial n>0, \partial P / \partial e^{*}>$ 0 , and totally differentiating (15), one obtains

$$
\frac{d e^{*}}{d n}=-\frac{K / R+\partial P / \partial n}{\partial P / \partial e^{*}}<0
$$

Therefore, the deterrence (no-attack) condition of the predator is given by a negative relation between the army size $n$ and the commitment effort of the victim, $e^{*}$ in its safety strategy. Risky effort and the size of the army appear as substitutes from the point of view of the national defence policy. Intuitively, the limited defence capacity of a victim can be compensated by a strong fighting effort.

Given the information of the victim's army size and the commitment of its soldiers, there is a unique probability for the predator to winning the war. The threshold army size for deterrence is derived in what follows.

Recalling (6) and (14), the indifference condition can be re-written as

$$
n \sqrt{\theta m n}=\frac{R}{K} m
$$

which can be solved as

\footnotetext{
${ }^{30}$ The approach in Section 3 considers the case known as honest signalling with separating equilibrium earlier analysed by Bergstrom and Lachmann (2001), among others. They derived the necessary and sufficient conditions for the alarm calls of the whatchful babbler where the function of the signal is to deter predation and where the predator takes into account the alarm call that has been sent.
} 


$$
n=\left(\frac{R}{K}\right)^{2 / 3} m^{1 / 3}\left[\sqrt{\frac{1}{\theta}}\right]^{2 / 3}
$$

We can state

PROPOSITION 3. Under honest signalling concerning the degree of commitment to defence, there is a unique solution for the optimal size of the victim's army to deter an attack. The army size needed to deter an attack is larger, the lower is intertemporal altruism $(\partial n / \partial \theta<0)$, the greater is the rent at stake $(\partial n / \partial R>0)$, the less costly is the war for the predator $(\partial n / \partial K<0)$ and the larger is the army of the predator $(\partial n / \partial m>0)$.

PROOF. From above.

Notice that, strong fighting effort reduces the required recruitment to obtain deterrence, $\partial n / \partial \theta<0$.

What the attacking enemy is interested in is its winning probability of war, namely the military strength of the victim, $n e^{*}$. It depends on the intertemporal altruism of the victim army,

$$
\frac{\partial(n e *)}{\partial \theta}=n\left(\frac{\partial e *}{\partial \theta}\right)+\left(\frac{\partial n}{\partial \theta}\right) e *\left[1+\varepsilon_{e * n}\right],
$$

where the first term, the effect of altruism on the figting effort, is positive while the second term, the effect of altruism on the policy decision on the army size, is negative. The latter effect depends on the elasticity of the risktaking by the soldiers on the army size, $\varepsilon_{e * n}<0$. In the model world of the current paper, the second term can be positive or negative. It is plausible, however, that it cannot outweigh the effect of the first term. The next sections can therefore safely be discussed in terms of the following assumption,

ASSUMPTION 1. Strong intertemporal altruism in the defending army increases the probability for the victim to win the war.

\section{Information Asymmetry: Signalling with the Army Size}

In the above, it has been taken that the victim is able to truthfully communicate to the predator its commitment to defend, or alternatively that the 
predator is able to perfectly monitor the commitment of the victim. The commitment of soldiers is determined by altruistic preferences, basically through the $\theta$-parameter. Victims with different $\theta$-preferences have a different ability to provide security for their citizens. If anything, this parameter, however, is private information of the soldiers. This implies that it may appear a difficult task to communicate the strength of the altruistic motive to the predator, and thereby the risk-taking by the soldiers. A credible signal would be helpful. In the current model, the natural signal is the army size $n$ which has been shown to have a systematic effect on the risk taking incentive. ${ }^{31}$

In this section, the information asymmetry is introduced into the analysis. The type of victim is alternatively a high- $\theta$ victim or a low- $\theta$ victim with probabilities $p_{H}$ and $p_{L}$ where $p_{H}+p_{L}=1$. It is assumed that the commitment of soldiers in the victim country, $e^{*}$, determined by intergenerational altruism $\theta$, cannot necessarily be truthfully predicted by the predator. The victim has the option of investing in a costly signal to convince the predator of its ability to defend. The size of the army provides a costly and therefore credible signal. We show in this section that a large defence army can reduce the probability of an attack in a pooling equilibrium for both types of victims. Subsequently, the qustion is raised as to whether a separating equilibrium can exist.

The game in this section is a Bayesian extensive game with observable actions, and it has the following structure: there are two players, a predator and a victim, and the game is played in three stages. In stage 0 , nature chooses the type of victim (high-or low- $\theta$ ). The victim is informed of its type. The value of $\theta$ is private information to the defender. In stage 1 , the victim undertakes an action in terms of how large an army to build. Thus, the pre-war communication takes place in stage 1 . The investment is costly and the army size can operate as a means for the defender to communicate (to signal) its willingness to defend to the predator. In stage 2, the predator either attacks or does not. The strategy space of the predator therefore consists of a discrete choice $\{$ attack, do not attack\}; the strategy space of the victim arises from an investment in the army \{sufficient to deter the attack, accept the war but resist the attack\}. We suggest that two types of perfect Bayesian equilibrium can exist.

\footnotetext{
${ }^{31}$ Other potential signals include the technology stance of the army, the skills of the soldiers, and their training.
} 
(a) Pooling equilibrium with no signaling Consider the case where the predator knows that the victim is one of two potential types $\left(\theta_{L}, \theta_{H}\right)$ with known probabilities $\left(p_{H}, p_{L}\right)$. Intuitively, it is plausible that the high- $\theta$ country which would have lessof a reason to have a large army than a low- $\theta$ country because its fighting incentive is greater. We suggest, however, that a pooling equilbrium exists when both types of victims preferring deterrence, choose the same army size say $n_{H}^{*}=n_{L}^{*}=n^{*}$, and where the predator is indifferent between attacking or abstaining from the attack. We show,

PROPOSITION 4. (Pooling equilibrium). There is a unique size for the victim's army which is sufficient to create deterrence for both types. The type $H$ victim suffers from the informational constraint of the predator as a result of the negative externality from the possibility of being of type L.

PROOF. Using (14) and (15), the zero profit indifference condition of the predator can be written as

$$
\pi_{P}=\left[p_{H} \frac{m}{\sqrt{\theta_{H} n m}}+p_{L} \frac{m}{\sqrt{\theta_{L} n m}}\right] R-n K=0 .
$$

This is an algebraic equation in the army size $n$. The first term in (18) is monotonically declining in $n$, while $n K$ is monotonically increasing in $n$. Their intersection, say $n *$, provides the unique solution in terms of the army size, expressed as

$$
n *=\left(\frac{R}{K}\right)^{2 / 3} m^{1 / 3}\left[p_{H} \sqrt{\frac{1}{\theta_{H}}}+p_{L} \sqrt{\frac{1}{\theta L}}\right]^{2 / 3} .
$$

In this solution, the army size of both types of victims is positively related to the value of its resource, $R$, and the military strength of the predator, $m$, but inversely related to the cost of attack for the predator, $K$. However, an expansion of the military strength of the attacker calls for less than a proportional increase in the defender's army. The army size is negatively related to the intertemporal altruism of the victim. We notice that when informational restrictions create confusion for the predator, a country with a low commitment to defend exerts a negative externality on the country with a high commitment. The latter country suffers because it has to choose a higher tax rate and overinvest in its army to create deterrence. The smaller is $\theta_{L}$, the greater has the army of not only of the victim of type low- $\theta$ but also of the high- $\theta$ type to be as $\partial n_{H} / \partial \theta_{L}<0$. In the absence of the information barrier, 
the high- $\theta$ country could afford to build a smaller army, as the willingness of its soldiers to defend, $\theta_{H}$, is great. To see this result formally, compare the army size under full information (17) and under imperfect information (19) to find out

$$
p_{H} \sqrt{\frac{1}{\theta_{H}}}+p_{L} \sqrt{\frac{1}{\theta L}}>p_{H} \sqrt{\frac{1}{\theta_{H}}}+p_{L} \sqrt{\frac{1}{\theta H}}=\sqrt{\frac{1}{\theta_{H}}} .
$$

Under perfect information, a victim of type $\theta_{L}$, would have to build a larger army for deterrence. To establish that the solution qualifies for a no-attack pooling equilibrium, it has to be shown that no incentives to deviate from it exist under reasonable out-of-equilibrium beliefs of the predator. Thus, if the predator observes a deviation from $n^{*}$, say $n<n *$, it might think that probably the victim is of type high- $\theta$. Such a belief does not, however, appear rational. The predator is aware that the victim is actually of type low $\theta$ with a positive probability $p_{L}$ and has an incentive to mimic the high- $\theta$ type. A more sensible belief for a predator is that the victim is of type high- $\theta$ with lower probability, $p_{H}<1$. This means that the high- $\theta$ cannot have an incentive to deviate from $n^{*}$. QED

To recall, the focus in the above case was based on that deterrence is the dominating strategy for the victim,

$$
W(\hat{C}, \hat{c}, C, c)>\max \left\{E[W(\hat{C}, \hat{c}, C, c)], W^{s}\right\}
$$

for both types. Verbally, the cost of war and the loss in the surrender have to be sufficiently high for both types of victims to detract the incentive to adopt fighting or surrendering as the optimal choice. ${ }^{32}$

In the real world, countries may build different defence capabilities when they cannot overlook a possible outside threat. In what conditions can a separating equilibrium exist?

(b) Separating equilibrium: signalling with the army size Above, it was suggested that differences in the country-specific intertemporal altruism, fighting intensities in short, can result in a pooling equilibrium. In this section, it is suggested that there may be reasons for a successful separation. This section therefore addresses the issue as to why it is the case that

\footnotetext{
${ }^{32}$ Explicit expressions for the threshold costs will not be stated as the argument is evident.
} 
countries facing a similar predator invest different amounts of resources in national defence..

Consider two potential victims $v=(i, j)$. Differentiate them now by their perceived costs of war $\left(k_{i}, k_{j}\right)$. The role of potentially different fighting intensities $\left(\theta_{i}, \theta_{j}\right)$ are discussed subsequently. The choices concerning the army size are $\left(n_{i}, n_{j}\right)$. Using (1) and (2), the consumption per capita can be solved as

$$
\hat{C}_{v}=\left(\frac{Y}{2}\right)\left[1-\frac{n_{v}}{N}\right], \quad v=i, j
$$

Investment in the army represents the opportunity cost in terms of foregone consumption. Building a large army, i.e., having a large defence budget as a proportion of the population, $n / N$, reduces consumption $\hat{C}$ through budget constraint. Without loss of generality, we simplify the notation by choosing $Y=2$. Denote the utility function of a civilian, undefined so far, by $U\left(\hat{C}_{v}\right)=U\left(1-\frac{n_{v}}{N}\right), U^{\prime}>0, U^{\prime \prime}<0$, with $\hat{C}_{v}$ obtainable if there is no war or if the war is won.

If the victim confronts a war, its probability of winning the battle is

$$
P_{v}=1-\sqrt{\frac{m}{\theta_{v} n_{v}}}, v=i, j
$$

where (6) and (14) has been used.

The suggested equilibrium has the following structure: one type of victim, say $i$, chooses a large army size with deterrence to match the indifference condition of the predator, making the predator judge that it is of type $i$ with deterrence as the national target, while the other type, $j$, chooses a small army size being exposed to an attack. Therefore, we should have $n_{i}>n_{j}$. To qualify for an equilibrium, the incentives for non-deviation have to be established. We let function $P_{i j}$ denote the army's success probability in war by if the victim $i$ mimics victim $j$. The variables $n_{i j}=n_{j}, n_{j i}=n_{i}$ denote the army sizes under mimicking. The non-mimic condition of the country $i$ is

$$
U\left(1-\frac{n_{i}}{N}\right)>P_{i j} U\left(1-\frac{n_{i j}}{N}\right)-n_{P} k_{i}
$$

where the right-hand side is the expected utility if victim $i$ chooses a small army, mimicking the victim $j$ and subjecting itself to an attack. 
Similarly, the non-mimic condition of the victim $j$ is

$$
U\left(1-\frac{n_{j i}}{N}\right)<P_{j} U\left(1-\frac{n_{j}}{N}\right)-n_{P} k_{j},
$$

Under what conditions can a pair $\left(0<n_{j}<n_{i}<N\right)$ exist that satisfies the non-mimic conditions? To find the answer, let us fix the value of the army size of the type $i$ victim, $n_{i}$, to satisfy the condition (17). Then ask under what conditions, separation is obtained, i.e. $n_{j}<n_{i}$.

Without loss of generality, adopt a parametrisation for the utility function $U()=.\log \left(\alpha+1-\frac{n_{i}}{N}\right)$. Consider the conditions around the given $n_{i}$ choosing $\alpha=\frac{n_{i}}{N}$, and making $U\left(1-\frac{n_{i}}{N}\right)=0$ and $U\left(1-\frac{n_{j}}{N}\right)=\log \left(1+\frac{n_{i}-n_{j}}{N}\right)>0$. Then, the first-non-mimic condition, (21), can be written as

$$
n_{p} k_{i}>\left(1-\sqrt{\frac{m}{\theta_{i} n_{j}}}\right) \log \left(1+\frac{n_{i}-n_{j}}{N}\right)>0 .
$$

When the perceived cost of war to the type $i$ victim is sufficiently large, no mimicking-incentive arises. With $n_{j i}=n_{i}$, the second non-mimic condition, (22), on the other hand, can be written as

$$
n_{p} k_{j}<\left(1-\sqrt{\frac{m}{\theta_{j} n_{j}}}\right) \log \left(1+\frac{n_{i}-n_{j}}{N}\right) .
$$

Therefore, when the perceived cost of war to the type $i$ victim is sufficiently small, no mimicking incentive arises. Differences in the fighting intensities have their roles to play as they interact with the probability of winning the war, (20). High $\theta_{i}$ raises the threshold for the cost of war in justifying the deterrence-target of country $i$. High $\theta_{j}$ reduces the maximum cost of war which justifies the non-deterrence strategy.

To summarise,

PROPOSITION 5. Perceived differences in the cost of war can lead to a separating equilibrium where a country facing a high cost of war builds a large army, while a country facing a lower cost of war builds a smaller army.

This result is expressed in a rather moderate way. The reason is that the deterrence condition (17) of type $i$ with its army size $n_{i}$ has to be satisfied in addition to the non-mimic condition. Moreover, for the $j$ type to be willing to have a small army, $n_{j}$, its army size has to fullfill the optimality condition to be derived in the next section. 
The existence of a separating equilibrium has been shown as conditional on the willingess of the $i$-type to use a large army to signal its perceived cost of war to the predator hence its willingness to defend. A separating equilibrium, however, may not exist univerally but is the subject of the conditions stated. However, it is in line with the natural view of why the documented survey results suggest strong national willingness to defend in some countries. The populations in potential victim countries may differ in terms of their willingness to defend. While such differences may result from differences in the valuation of the consumption relative to the national defence, the current model suggests that ultimately, such differences need not be imbedded in preferences but can instead be derived from differences in the perceived costs of wars or in the intertemporal altruism. ${ }^{33}$

\section{The Optimal Army Size Without Deter- rence}

In this section, the following question is raised: how many resources does a utilitarian government of a $j$ - type victim optimally allocate to the national defence, knowing that deterrence is lost and that the war takes place in equilibrium? A soldier career is more risky than a civilian career as a soldier faces the risk of death even when the country is successful in defending. It may therefore be that the civilians have to pay a premium to the defence population to implement such a social contract. The problem faced by a benevolent government is thus the potential interest conflict of the civilian population and the defence population. Both value the life of future generations. Moreover, both understand that a larger army means a greater probability of defeating the attacking predator if war breaks out. However, the civilian population finances the consumption of the defence population

\footnotetext{
${ }^{33} \mathrm{As}$ an example, Ukraine obviously had largely disregarded its investment in its defence before the current crisis. However, when the military hostilities began in 2014, its army was able to successfully resist the invasion of the Russian-backed attacking forces. Sweden is another case. Its defence budget aligns with the defence budgets of its neighbours. However, with the recently increased tension in the Baltic Sea area, it realised that its abolishment of the draft army and the demilitarisation of its Gotland island were mistakes. It has tried to reintroduce both, but has failed in its attempts of rebuilding of its defence force through the draft.
} 
and tends to prefer a small army. The defence population prefers a larger army, as this raises the survival of an individual soldier, though understanding that the per capita consumption of both populations has to be cut down when the size of the army becomes bigger. To settle the interest conflict, a social contract is needed. To facilitate the implementation of the defence policy, the equality of the expected utilities across the careers was suggested in Section 2.1 as the criterion for the the structure of a social contract.

Denote the expected utilities of civilian and defence populations as

$$
\begin{gathered}
E[U]=P[U(\hat{C}(Y, \hat{c}, T, n))+U(\hat{c})]=2 P U(.) \\
E[V]=\left[1-e^{*}-\sigma(.)\right] u(C)+\theta P\left(n, e^{*}\right) v(c) .
\end{gathered}
$$

From the budget constraint $(N-n) T=n(C+c)$ and from $C=c$, the consumption of the military class is $C=c=\left(\frac{N-n}{2 n}\right) T$. If the social contract imposes equality between the expected utilities of the populations, we have

$$
E[U]=E[V] .
$$

Summing up the expected utilities of the civilian adults and children and of the military adults and children, the maximisation problem of a utilitarian government is

$$
\begin{gathered}
\max _{n, T} L(n, T, \lambda, \mu)=2(N-n) P U+n E[V]-n_{P} k+\lambda\left[T-\frac{2 n}{N-n} C\right] \\
+\mu\{2 P U-E[V]\} .
\end{gathered}
$$

The shadow prices $\lambda>0$ and $\mu \gtrless 0$ have been introduced to price the two constraints. ${ }^{34}$

To study the first-order conditions for the interior optimum, recall from the soldier's first-order condition that $\partial V / \partial e^{*}=0$, hence

$$
\frac{\partial V}{\partial n}=\frac{\partial V}{\partial e^{*}} \frac{\partial e^{*}}{\partial n}=0
$$

\footnotetext{
${ }^{34}$ Without the latter constraint, the problem is a utilitarian one. With the equalitarian constraint, the solution to the maximisatiohn problem is different except by chance. Depending on whether it is the civilian class or the soldier class whose share has to be cut back, the associated shadow price $\mu$ may be positive or negative.
} 


$$
\frac{\partial V}{\partial T}=\frac{\partial V}{\partial e^{*}} \frac{\partial e^{*}}{\partial n} \frac{\partial n}{\partial T}=0
$$

Then, the social first-order conditions are simplified to

$$
\begin{gathered}
\frac{\partial L}{\partial n}=-2 P U+2(N-n) P_{n} U+E[V]-\lambda \frac{2 C}{(N-n)^{2}}+2 \mu P_{n} U=0 \\
\frac{\partial L}{\partial T}=2(N-n) P U_{T}+\lambda+2 \mu P U_{T}=0 \\
\frac{\partial L}{\partial \lambda}=T-\frac{2 n}{N-n} C=0 \\
\frac{\partial L}{\partial \mu}=E[U]-E[V]=0 .
\end{gathered}
$$

A notation $U_{T}=U_{\hat{C}} \hat{C}_{T}$ has been introduced in (28). From (28), the marginal social valuation of the tax revenue is related to the marginal utility of the civilian population as

$$
\lambda=-2(N-n+\mu) P U_{T}>0,
$$

where $U_{T}<0$. Evaluate the derivative $\partial L / \partial n$ at $n=0$ and at $n=N$,

$$
\begin{aligned}
& \left.\frac{\partial L}{\partial n}\right|_{n=0}=2 N P_{n} U+E[V]-\lambda \frac{2 C}{N^{2}}+2 \mu P_{n} U \\
& \left.\frac{\partial L}{\partial n}\right|_{n=N}=-2 P U+E[V]-\lambda \frac{2 C}{(0)^{2}}+2 \mu P_{n} U .
\end{aligned}
$$

For logical reasons, the first condition surely has to be positive; the second one is definitively negative. As the functions are monotone, a unique interior solution arises with $0<n^{*}<1$.

The optimal tax theory has taught our profession that it is not always possible to arrive at explicit closed-form solutions for the optimal tax rates, say. The best one can do it is to characterize the optimal solution. This is also the case here. Intuitively, the first term in (27) represents the marginal 
social cost of having a larger national army $n$ as the number of civilians is reduced. Therefore, the first term is negative. The second term in (27) represents the security gain to the civilians from a larger army in terms of a greater probability of a successful war. The third term represents the social gain for each soldier arising from a marginal increase in the army size. The fourth term states that when the defence budget increases it enhances the national security, but this increase comes with a higher tax liability cost to be collected from the civilians. The final term is the required compensation for the civilian population from an increased army size.

Denote the elasticity of the probability of the victory as

$$
\frac{\partial P}{\partial n} / \frac{P}{n}=\varepsilon_{P n}>0
$$

and the elasticity of the utility with respect to the tax cost as

$$
\frac{\partial U}{\partial T} / \frac{U}{T}=\varepsilon_{U T}<0
$$

Then, the first-order condition with respect to the army size can be used to arrive at the premium in terms of the expected utilities of the military and the civilian populations. Denote

$$
\frac{E[V]}{2 P U}=\eta
$$

As $2 C / T=(N-n) / n$, the first-order condition (27) can be evaluated to arrive at

$$
\eta=1-\left(\frac{N-n+\mu}{n}\right)\left(\varepsilon_{P n}+\frac{1}{N-n} \varepsilon_{U T}\right) .
$$

In equilibrium, it must hold $\eta=1$ if the social contract dictates equality of the expected utilities for both professions. If the equality would not be the aim, the premium should be bigger or smaller than 1 as $\varepsilon_{P n}>0$ and $\varepsilon_{U T}<0 .{ }^{35}$ In equilibrium with $\eta=1$ implying $\varepsilon_{P n}+\varepsilon_{U T} /(N-n)=0$, the size of the army satisfies

$$
n=N-\frac{\left|\varepsilon_{U T}\right|}{\varepsilon_{P n}} .
$$

\footnotetext{
${ }^{35}$ If the welfare maximising $\eta$ is smaller than 1 , it cannot obviously be imposed on a voluntary basis.
} 
To summarise:

PROPOSITION 6. The social contract dictates that the optimal army size of a victim of $j$-type is negatively related to (the absolute value of) the elasticity of the utility with respect to the tax cost and positively related to the elasticity of the probability of the victory with respect to the army size.

Finally, we conclude that the effect of intergenerational altruism on the optimal army size remains ambiguous and depends on the preferences of the civilian population, $U$. A higher $\theta$ raises both the denominator and the numerator in (34)

\section{Final Remarks}

Creating the national security requires that part of the population be recruited into the military as soldiers with a commitment to undertake risky operational actions if the country becomes the victim of a hostile predator. The current paper has shown that in a commitment equilibrium, the defending army, particularly a small one, fights hard. As an implication, the paper has offered a novel theory of deterrence and defence policy. It was shown that in the absence of informational constraints, there is a unique army size, sufficient enough to deter an attack. Under informational restrictions, a pooling equilibrium may exist where a victim with strong intergenerational altruism has to overinvest in its army. Instead, for deterrence, the victim with a more limited altruism can free ride on the information gap of the predator, investing less in the defence than it would have to do under full information. It was also shown that the case of separating equilibrium may exist in which a large army can be used as a signal of a high willingness to defend particularly when the cosr of war is perceievd to be large. A victim with a smaller willingness to defend, however, risks a military confrontation with the enemy. The paper has thus arrived at the remarkable result that the socially optimal defence policy does not need to provide a sufficient deterrence against the potential predator. The analysis and results point to the role of (implicit) pre-conflict communication between a potential victim and a potential predator. For deterrence, credible signals concerning the willingness to defend have to be developed particularly if the potential predator is uncertain about the type of victim it is targeting. The army size may operate as such a signal. 


\section{References}

Alesina, A., and Spolaore, E., (2003), The Size of Nations, The MIT Press, Cambridge MA.

Arce, D.G., Kovenock, DF., and Robertson, B., (2012), "Weakest-Link Attacker-Defender Games With Multiple Attack Technologies." Naval Research Logistics, 59(6): 457-469.

Becker, G.S., (1991), A Treatise on the Family, Cambridge, MA: Harvard University Press.

Benson, B.V., Meirowith, A., and Ramsay, K.W., (2014), "Inducing Deterrence through Moral Hazard in Alliance Contracts", Journal of Conflict Resolution, 58.2, 307-335.

Bergstrom, C.T., and Lachman, M., (2001), "Alarm Calls as Costly Signals of Antipredator Vigilance: the Watchful Babbler Game", Animal Behavior 61 (3): 535-543.

Beviá, C. and Corchón, L.C., (2008), "Peace Agreements without Commitment", Working Paper 08-15, Universidad Carlos III De Madrid.

Bueno de Mesquita, B., and Lalman, D., (1992), War and Reason, Yale University Press.

Bueno de Mesquita, B., Smith, A., Siverson, R., and Morrow, J., (2003), The Logic of Political Survival, The MIT Press, Cambridge MA.

von Clausewitz, C., (1943), On War, Random House, New York.

Dawkins, R., (1976), The Selfish Gene, Oxford: Oxford University Press.

Fornari, F., (1975), The Psychoanalysis of War, Indiana University Press, Bloomington.

Hamilton, W.D. (1964). The genetical evolution of social behaviour, I \& II. J. Theor. Biol.7, 1-52.

Hirshleifer, J., (1991) "The Paradox of Power", Economics and Politics 3, 177-200. 
Hirshleifer, J., (1998), "The Bioeconomic Causes of War", Managerial and Decision Economics, 19, No. 7/8, 457-466.

Jackson, M.O., and Morelli, M., (2007), "Political Bias and War", American Economic Review, 97, No.4, 1353-1373.

Kahneman, D., and Tversky, A., "Prospect Theory: An Analysis of Decision under Risk", Econometrica, 47, 1979, 263-291.

Kanniainen, V., and Ringbom, S., (2016), "Security Gradient and National Defense - The Optimal Choice between a Draft Army and a Professional Army", Defence and Peace Economics, 27, March 1, $1-21$.

Kolmar, M., (2013), "Group Conflicts. Where do we stand?", Universität St.Gallen, Discussion Paper no. 2013-31.

Konrad, K. A., (2009), Strategy and Dynamics in Contests, Oxford University Press, Oxford.

Levine, D.K., and Modica, S., (2016), "Peer Discipline and Incentives Within Groups", Journal of Economic Behavior and Organization, 123, 19-30.

Levy, J.S., (1989), "The Causes of War: A Review of Theories and Evidence", in P.E.Tetlock, J.L.Husbands, R.Jervis, and P.C.Stern, eds. Behavior, Society, and Nuclear War, vol I, New Yourk: Oxford University Press, 210-333.

Nokkala, A., (2014), Kyky ja tahto (Ability and Will) Docendo, Jyväskylä.

Poutvaara, P., and Wagener, A., (2007), "To Draft or Not to Draft? Inefficiency, Generational Incidence, and Political Economy of Military Conscription", European Journal of Political Economy, 23(4), 975-987.

Salo, M., (2011), United We Stand - Divided We Fall: A Standard Model of Unit Cohesion, Publications of the Department of Social Research, University of Helsinki, 2011:6.

Schelling, T. C., (1960), The strategy of conflict. Harvard University. 
Schelling, T.C., (1965), Arms and Influence, Yale University Press, Yale University.

Shils, $\quad$ E.A. and Janowitz, M., (1948): Cohesion and Disintegration in the Wehrmacht in World War II, Public Opinion Quarterly, 12 (2). Also published in: Burk, J., and Segal, D., R. (eds) (2012): SAGE Library of Military and Strategic Studies: Military sociology. (Vols. 1-4) Volume 1: 135-172. London: Sage Publications.

Siebold, G. L., (2007): The Essence of Military Group Cohesion, ArmedForcesSociety, 33 (2): $286-295$.

Sinkko, R., (2015), Maanpuolustustahto asevelvollisen koulutuksen ja palveluksen onnistumista selittävänä tekijänä (Commitment to Defend and Its Implications for Success of Service), National Defence University, Helsinki, Series 1: Research Publications No. 2.

Smith, A., (1853), The Theory of Moral Sentiments, London: Henry G. Bohn.

Spolaore, E., and Wacziarg, R., (2016), "War and Relatedness", The Review of Economics and Statistics, 98(5), 925-939.

Sutherland, B., (ed.), (2011), Modern Warfare, Intelligence and Deterrence. Profile Books, London, England.

Tullock, G., (1967), "The welfare costs of tariffs, monopolies, and thefts." Western Economic Journal, 5:224-232.

Tullock, G., (1980), "Toward a Theory of the Rent-Seeking Society", in Efficient Rent-Seeking, 97-112, Texas A\&M University Press, College Station TX.

Wong, L., Kolditz, T., A., Millen, R., A., and Potter, T., M. (2003): Why They Fight: Combat Motivation in the Iraq War. Carlisle, PA: Strategic Studies Institute. 